\title{
Thermal Ablation in the Management of Colorectal Cancer Patients with Oligometastatic Liver Disease
}

\author{
Elena Nadia Petre Constantinos Sofocleous \\ Department of Interventional Radiology, Memorial Sloan Kettering Cancer Center, New York, NY, USA
}

\section{Keywords}

Percutaneous tumor ablation - Colorectal liver metastases . Long-term outcomes

\section{Summary}

Background: Surgical resection of limited colorectal liver disease improves long-term survival and can be curative in a subset of selected cases. Image-guided percutaneous ablation therapies have emerged as safe and effective alternative options for selected patients with unresectable colorectal liver metastases (CLM) that can be ablated with margins. Ablation causes focal destruction of tissue and has increasingly been shown to provide durable eradication of tumors. Methods: A selective review of literature was conducted in PubMed, focusing on recent studies reporting on the safety, efficacy, and longterm outcomes of percutaneous ablation modalities in the treatment of CLM. The present work gives an overview of the different ablation techniques, their current clinical indications, and reported outcomes from most recently published studies. The 'test of time' concept for using ablation as a first local therapy is also described. Results: There are several thermal ablative tools currently available, including radiofrequency ablation (RFA), microwave ablation, and cryoablation. Most data to date originated from the application of RFA. Adjuvant thermal ablation in the treatment of oligometastatic colon cancer liver disease offers improved oncologic outcomes. The ideal CLM amenable to percutaneous ablation is a solitary tumor with the largest diameter up to $3 \mathrm{~cm}$ that can be completely ablated with a sufficient margin. 5-year overall survival rates up to $70 \%$ after ablation of unresectable CLM have been reported. Pathologic confirmation of complete tumor necrosis with margins over $5 \mathrm{~mm}$ provides best long-term local tumor control by thermal ablation. Conclusion: Current evidence suggests that percutaneous ablation as adjuvant to chemotherapy improves oncologic outcomes of patients with CLM. For small tumors that can be ablated completely with clear margins, percutaneous ablation may offer outcomes similar to those of surgery.

(c) 2017 S. Karger GmbH, Freiburg

\section{Introduction}

Image-guided thermal ablation has gained wide acceptance for the treatment of primary and metastatic malignancies, generally in selected patients with non-resectable disease. Resection of liver metastases can be curative with ablative therapies playing an adjuvant role for patients who are poor surgical candidates, or used in conjunction with resection to completely debulk the disease. A randomized controlled trial from 2012 showed a progression-free survival (PFS) benefit for patients with colon cancer hepatic metastases treated with adjuvant thermal ablation (with and without resection) with standard chemotherapy when compared to those treated with systemic chemotherapy only [1]. A longer follow-up of the same study population documented a survival benefit for the patient group undergoing ablation of the liver metastases in addition to standard-of-care chemotherapy [2]. The safety and efficacy of local tumor ablation was established in several uncontrolled studies. Patient survival after percutaneous ablation seems comparable to that of surgical series (up to $55 \%$ at 5 years) in selected patients with small liver volume disease that can be treated with sufficient margins [3-5]. Ablative therapies minimize the destruction of healthy tissue as compared to surgical resection. This is an important parameter for patients with underlying cirrhosis or steatohepatitis from prolonged chemotherapy exposure as well as those with liver tumor progression after prior hepatectomy [6, 7]. Thermal ablation has additional advantages as a treatment for oligometastatic hepatic disease:

\section{KARGER}

(c) 2017 S. Karger GmbH, Freiburg
Elena Nadia Petre, MD

Department of Interventional Radiology

Memorial Sloan Kettering Cancer Center

1275 York Ave, Suite H118, New York, NY 10065, USA

petree@mskcc.org 
(1) It can be repeated to treat additional progression.

(2) It does not impact surgical eligibility for those that can be resected for future progression.

(3) It does not require prolonged chemotherapy interruption.

(4) It maintains the patients' quality of life.

This is particularly important in view of the nature of the disease and the high likelihood that recurrences requiring repeated treatment will occur even after resection with sufficient margins $[8,9]$.

\section{Indications and Contraindications}

The indications and contraindications of tumor ablation are in line with the accepted definition for oligometastatic disease. The most common indications for image-guided ablation are: limited number $(<4)$ and small size $(<5 \mathrm{~cm}$ in largest diameter) of metastases in patients that cannot undergo or refuse surgery [10]. The ideal tumor for percutaneous ablation is a solitary lesion with largest diameter up to $3 \mathrm{~cm}$. A tumor size up to $5 \mathrm{~cm}$ may be acceptable for ablation although multiple overlapping ablations will be required to achieve complete ablation with a sufficient surrounding margin (ideally a $1-\mathrm{cm}$ and at the very minimum a $5-\mathrm{mm}$ margin all around the tumor should be created). There is no absolute number of tumor eligibility but most series agree that patients with more than four simultaneous liver metastases are not good candidates for image-guided percutaneous ablation.

Contraindications of ablation are:

(1) No safe access of the ablation needle to the tumor despite protective maneuvers such as hydrodissection.

(2) Anticipated collateral damage to structures nearby the tumor that cannot be protected with additional maneuvers.

(3) Uncorrectable coagulopathy.

(4) A relative contraindication is the inability of a patient to undergo general anesthesia.

(5) Diffuse metastatic disease.

\section{Ablation Modalities}

Different ablation technologies, including radiofrequency ablation (RFA), microwave ablation (MWA), laser, and cryoablation, use heat or freezing as a means to achieve cell damage and death of the target tumor. More recently, irreversible electroporation (IRE), a non-thermal technology, has been applied for liver tumor ablation, including selected colorectal liver metastases (CLM) that were not amenable to thermal ablation due to high risk for collateral damage.

\section{Radiofrequency Ablation}

RFA is the most widely employed and most studied tumor ablation technique. RFA delivers high-frequency alternating electric current through a needle electrode placed within a target lesion. This causes local ionic oscillation and tissue heating that leads to protein denaturation when the temperature exceeds $50{ }^{\circ} \mathrm{C}$. At $70{ }^{\circ} \mathrm{C}$ thermal coagulation occurs, and this thermal injury causes cell death. When the temperature reaches $100{ }^{\circ} \mathrm{C}$, tissue desiccation (charring) occurs, resulting in high tissue impedance, which limits the amount of energy that can be delivered in the tumor, thus preventing expansion of the lethal temperature within tissue. Tissue desiccation is one of the technical limitations of RFA. Another important limitation is the 'heat-sink' effect that occurs when ablating tumors near the blood vessels.

RFA has been used to control CLM successfully in selected patients that were often ineligible for resection [11-15]. There is a growing evidence that for small tumors that can be ablated completely with clear margins, RFA may be able to provide results similar to those of surgery $[4,5,16-19]$.

The local recurrence rate after RFA varies widely between $2 \%$ [20] and $60 \%$ [21] and has been an important limitation for the widespread use of RFA [20-25]. Size of the lesion, distance from major vessels, and ablation margins (fig. 1) are well known factors that have been associated with local tumor control. A tumor size up to $3 \mathrm{~cm}$ is now established to be the ideal candidate for RFA, with oncologic outcomes similar to those achieved by surgical resection $[16,19,26-$ 29]. A recent prospective study documented a local tumor progression (LTP) rate of 3\% within 12 months and a local tumor PFS over $95 \%$ at 30 months after ablation of CLM with margins over $5 \mathrm{~mm}$ and biopsy-proven complete tumor necrosis [30]. These results compare favorably with reported recurrence rates after resection.

Due to the 'heat-sink' phenomenon, as described above, tumors adjacent to vessels larger than $3 \mathrm{~mm}$ in diameter are at relatively increased risk for ablation failure and LTP [26, 28, 31, 32]. Similarly to the surgical margin [33], the ablation margin has been associated with local tumor control [19, 26, 34-36]. A minimal ablation margin $>5 \mathrm{~mm}$ and ideally $\geq 10 \mathrm{~mm}$ in all directions around the target CLM on the 4-8 weeks post-RFA computed tomography (CT) was associated with improved local tumor control [19, 36]. A study from 2016 indicated LTP rates of 15 and 5\% for tumors ablated with 5-10 and $>10 \mathrm{~mm}$ margins (ablation with clear margins: A0), respectively, within the 55-month follow-up period after RFA [19]. Similarly, a prospective single-arm trial with biopsy of the ablation zone immediately after CLM ablation reached a 97\% local PFS at the 30-month follow-up after ablation of CLM with pathologic confirmation of complete tumor necrosis with ablation margins $>5 \mathrm{~mm}$ [30]. These results compare favorably to those after resection of liver metastases $[37,38]$. Immediately after RFA the ablation margins are recommended to be at least $10 \mathrm{~mm}$ all around the target tumor, whenever safe and feasible [36].

Median overall survival times over 30 months for thermal ablation are superior when compared to those of unresectable historical controls treated by chemotherapy alone $[12,39,40]$. There is a single randomized clinical trial comparing RFA combined with systemic chemotherapy to systemic chemotherapy alone as first-line therapy for CLM [1]. The benefit of RFA in combination with systemic chemotherapy is reflected in a statistically significant prolongation of median PFS to 16.8 months for the combined arm compared to 9.9 for the chemotherapy-only arm. Overall patient survival for the combined treatment was $61.7 \%$ compared to $57.6 \%$ for the chemotherapy-only arm at 30 months. This modest prolongation did not 

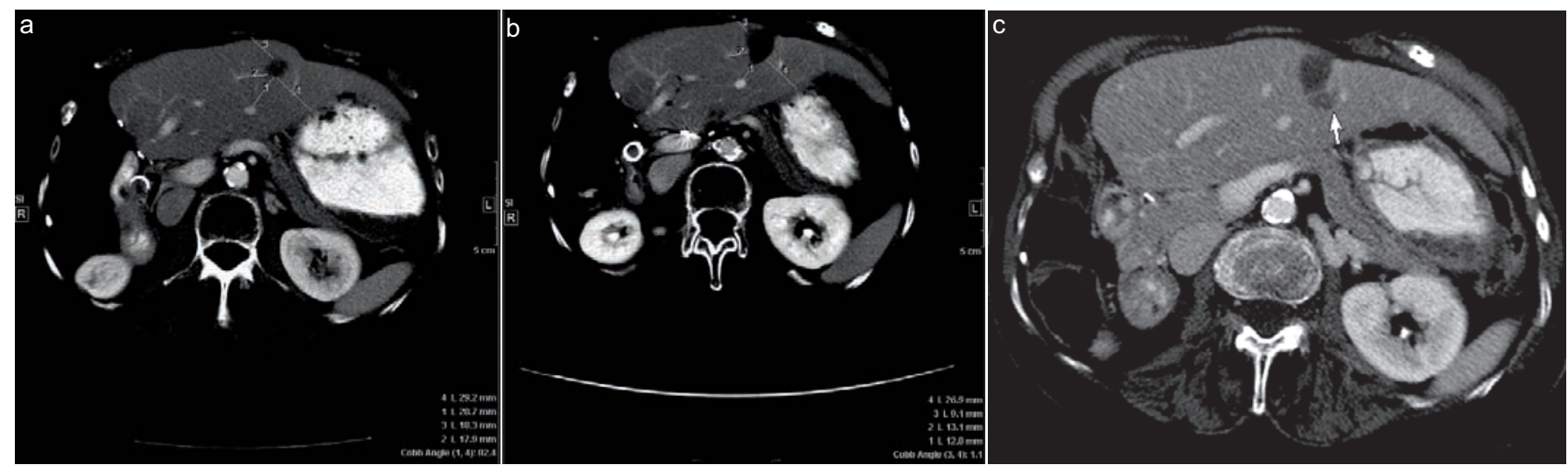

Fig. 1. Value of ablative margin assessment. 73-year-old woman with a $2 \mathrm{~cm}$ colorectal liver metastasis in segment 2 of the liver for radiofrequency ablation. Ablative margin measurement a before ablation - distances 1, 2, 3, and 4 were measured from the edges of the tumor to the chosen landmarks; $\mathbf{b} 7$ weeks post-ablation computed tomography - distances 1,2,3, and 4 were measured from the edges of ablation defect to the same landmarks. The corresponding distances were subtracted and the smallest value was defined as the minimal margin, in this case distance $4(29.2-26.9=2.3 \mathrm{~mm})$. c At the 5 -month follow-up, computed tomography scan shows, despite the fact that the ablation zone decreased in size, that there was a new hypodense lesion adjacent to the ablation zone at the site of minimal margin (arrow), consistent with local tumor progression.

reach significance in a study that was not powered to address this and with a follow-up time of only 30 months [41]. In a subsequent long-term follow-up, a significant prolongation of patient survival for patients treated with RFA in addition to systemic chemotherapy (35\% of patients were alive at a median follow-up of 9.7 years in the RFA + systemic chemotherapy arm vs. $10 \%$ in the chemotherapyonly arm) was presented at the ASCO Annual Meeting 2015 [2, 42].

\section{Microwave Ablation}

MWA utilizes high-frequency waves similarly to radiofrequency but in much higher range between $900 \mathrm{MHz}$ and $2.4 \mathrm{GHz}$. These high-frequency waves cause water molecules to oscillate, thus creating friction, causing heat, and resulting in tissue destruction by coagulation necrosis similarly to RFA. MWA presents at least some theoretical advantages over RFA, such as: lower susceptibility to the 'heat-sink' phenomenon and lower heat dissipation caused by charring, thereby achieving larger areas of ablation in a relatively shorter period of time. For these reasons, MWA is thought to be more efficient in the treatment of larger lesions and for targets located near large vessels when compared to other thermal ablation modalities [43]. With regard to overall survival, intraoperative MWA have demonstrated similar results to surgery in retrospective series $[44,45]$. To date there is a single randomized trial comparing MWA to hepatic resection in patients with CLM [46]. The mean survival time was 27 months in the MWA group versus 25 months in the surgery group. The mean disease-free interval was 11.3 months in the MWA group versus 13.3 months in the surgery group. These differences were not statistically significant. Procedure-related complication rates were similar between the groups, except for blood transfusion requirement which was significantly more frequent in the surgery group [46]. A retrospective matchedcohort study comparing open operative MWA with RFA for the treatment of 254 CLM (127 tumors in each group) resulted in statistically significant lower local recurrence rates for MWA versus RFA at 2 years (6 vs. 20\%, p = 0.01) [47]. MWA and RFA groups were comparable in terms of age, gender, median number of tumors treated, proximity to major vessels, and postoperative complication rates. The majority of patients (90\%) received preoperative systemic chemotherapy, and a similar proportion of patients in both arms had hepatic arterial infusion therapy (54 and 46\% for RFA and MWA, respectively). A statistically significant longer follow-up period in the RFA versus MWA groups and the lack of ablation margin calculations and stratification in each group might have confounded the results. Complications were similar between the two groups [47]. More recently, a meta-analysis [48] that included 10 prospective and 6 retrospective studies evaluating MWA and RFA treatment outcomes in patients with primary and metastatic liver tumors found a 6-year survival benefit for patients treated with MWA compared to RFA (odds ratio 1.64; 95\% confidence interval (CI): 1.64-2.35, $\mathrm{p}=0.007$ ) and no difference overall in local recurrence rate and complete ablation, as well as in overall survival and disease-free survival at 1-5 years. MWA showed significantly lower recurrence rates for liver metastases alone, and no differences were seen for hepatocellular carcinoma [48]. The metaanalysis inferred that MWA and RFA have similar long-term survival outcomes and safety profiles as evidenced by cohort studies; however, due to the limitations of these studies, randomized controlled trials are necessary to compare the two techniques. A recent study that compared LTP after RFA and MWA of CLM found no statistically significant difference between the two techniques (Shady W, Petre EN, Do KG, et al.; unpublished data). Close vascular proximity of the tumor was an independent factor for LTP after RFA (hazard ratio: 2.2; 95\% CI: 1.1-4.3, $\mathrm{p}=0.021$ ), but had no effect on MWA efficiency ( $p=0.43$ ), suggesting that MWA might be preferable to RFA for perivascular tumors (Shady W, Petre EN, Do KG, et al.; unpublished data).

\section{Cryoablation}

Cryoablation utilizes liquid nitrogen or argon administered through a needle electrode to decrease tissue temperature to lethal 
Fig. 2. Value of positron emission tomography/ computed tomography (PET/CT) guidance and immediate post-ablation assessment using PET/CT combined with margin assessment. 58-year-old man with a $1.8 \mathrm{~cm}$ colorectal liver metastasis in segment 3 of the liver. a Fused fluorodeoxyglucose $\mathrm{PET} / \mathrm{CT}$ images in a 58-year-old man with colorectal cancer liver metastasis prior to PET-guided ablation and $\mathbf{b}$ immediately post-ablation, showing no residual metabolic activity. c, d Margin assessment demonstrating that a minimal margin of at least $10 \mathrm{~mm}$ all around the tumor was created. $\mathbf{e , ~} \mathbf{f}$ 4-year follow-up imaging with contrast-enhanced CT (e) and PET/CT demonstrates no local tumor progression.
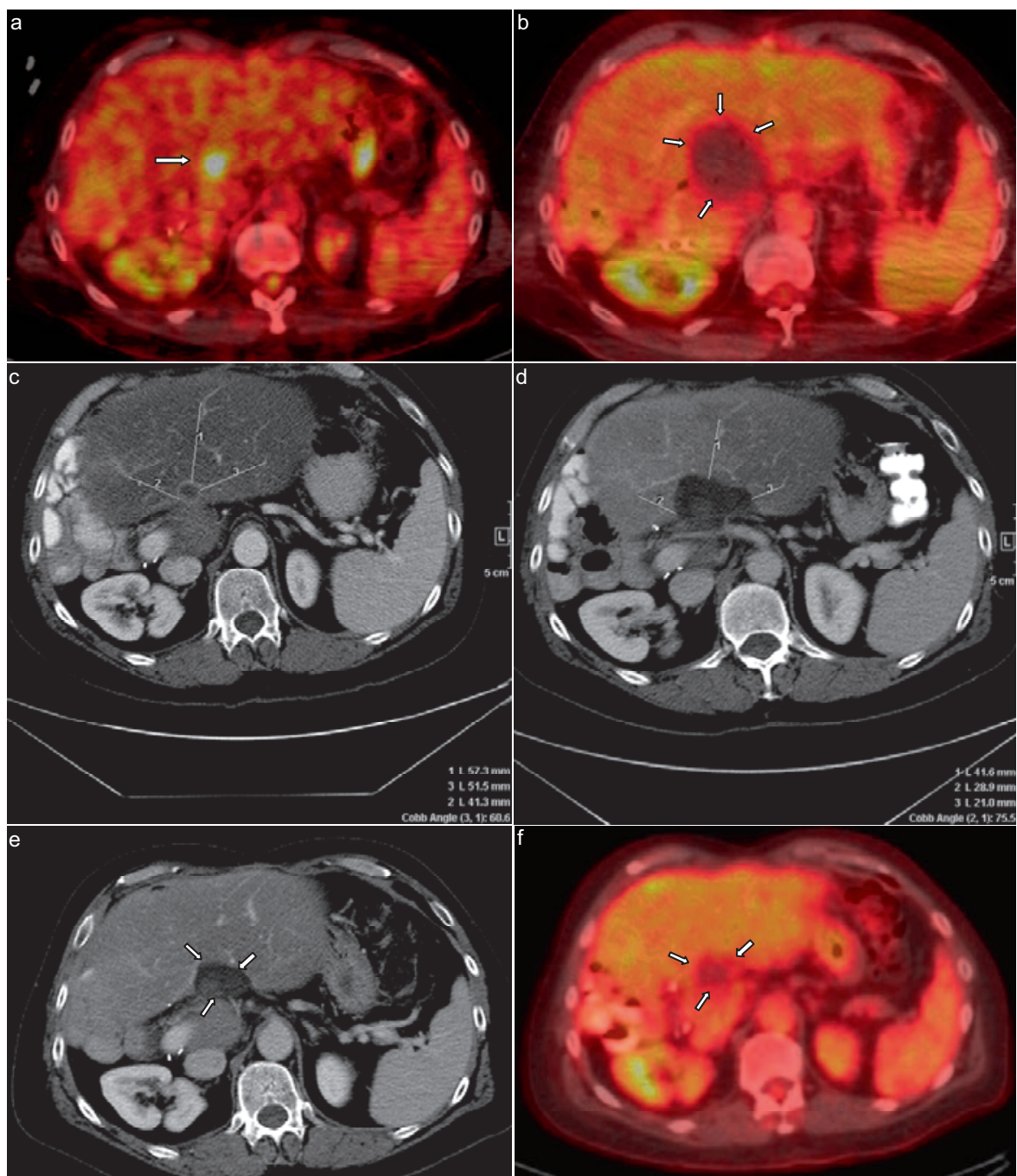

levels $\left(-20\right.$ to $\left.-40{ }^{\circ} \mathrm{C}\right)$. Repetitive cooling-thawing cycles result in disruption of the cell membranes, extra- and intracellular ice formation, hypoxia, and apoptosis. Similarly to RFA, flowing blood in the large-diameter vessels nearby can carry away the low thermal energy through convection, limiting the extent of cryoablation.

One of the advantages of this technique is the creation of ice balls that are visible under CT, ultrasonography, or magnetic resonance guidance, allowing monitoring of the ablation zone during the procedure. The appearance of the ice ball on imaging correlates with the tumor ablation margins. Tissue temperature at the periphery of the ice ball is cooled to $0^{\circ} \mathrm{C}$, a non-lethal level, while $5 \mathrm{~mm}$ inward the temperature reaches $-20^{\circ} \mathrm{C}$. Similarly to RFA, the operator should aim for creation of an ice ball that completely covers the targeted tumor with margins beyond the edge of the tumor in order to ensure complete ablation.

Cryotherapy alone or in combination with hepatic resection has been used in selected patients, resulting in oncologic outcomes comparable to surgery with clear margins $[49,50]$. Cryoablation applied to the edge of hepatic resections (edge cryotherapy) is frequently used in cases with 'close' margin, affording a 5-year survival rate of $31 \%$ for advanced colorectal cancer [51]. The same authors reported a 5 -year survival rate of $21 \%$ for the group that was treated with hepatic cryotherapy alone or in combination with liver resection, with curative intention [51]. These results are promising and suggest that with the use of cryotherapy more patients with CLM can be offered treatment resulting in similar survivals as those that undergo resection [52]. The only randomized trial [53] comparing cryotherapy and conventional surgery included 82 patients with CLM (among the 123 patients in the study). 3-, 5-, and 10-year survival rates for all patients were 60, 44, and $19 \%$ in the cryotherapy, and 51,36 , and $8 \%$ in the conventional surgery group, respectively [53]. Bang et al. [54] conducted a retrospective review of percutaneous cryoablation of liver, lung, and soft tissue oligometastatic sites of colorectal cancer origin. A total of 151 tumors were treated in 59 patients (116 liver, 33 lung, and 12 soft tissue tumors). The overall local recurrence rate was $12 \%$ ( $9 \%$ for liver, $18 \%$ for lung, and $8 \%$ for soft tissue). Median overall survival was 23.6 months with an estimated 3-year survival rate of $30 \%$, and the major complication rate observed was $8 \%$. The study also explored cost estimates for cryoablation and concluded that the procedure is cost-effective [54]. 


\section{Irreversible Electroporation}

IRE is a non-thermal ablation. Electroporation involves permeabilization of the lipid cellular membrane via application of ultrashort pulses of high electric current that create permanent openings (nanopores). Formation of permanent nanopores alters cellular components and causes lysis, loss of homeostasis, and cellular death. The extracellular matrix remains unperturbed, thus tissue architecture is preserved. In this manner, IRE avoids injury to the bile ducts and vessels within the organ, while still ablating tumors [55]. One of the key limitations of this technology in its current form is that it requires a minimum of 2 electrodes, placed parallel and spaced $1-1.5 \mathrm{~cm}$ apart in order to create any ablation zone. This requirement can be challenging when placing the electrodes through the intercostal spaces in order to reach and treat liver tumors.

The safety and efficacy of IRE for treating liver tumors has been shown in preclinical studies $[55,56]$, and recently when treating perivascular and peribiliary tumors in humans $[57,58]$. Clinical series that included patients with CLM have demonstrated a primary efficacy of $67-100 \%$ for tumors adjacent to major vascular/biliary structures [57-60] that could not be safely treated and would not qualify for thermal ablation. The risk of recurrence seems to be higher for tumors $>3 \mathrm{~cm}$ in size [58-60]. A 2014 retrospective review of 29 patients who underwent percutaneous IRE of 58 CLM showed a median PFS of 4 months, with estimated PFS and overall survival rates of 18 and $62 \%$, respectively, at 2 years [61]. Radiologic response by RECIST criteria was an independent predictor for local PFS and overall survival [61]. Current evidence, while encouraging, is still limited, with no randomized control trials. Moreover, most of the series included different organs and different pathologies, making it impossible to draw any generalized conclusion. Further study and understanding of the electric properties of different tissues is necessary in order to optimize the technique.

\section{Discussion}

The exact role of ablation in the management of CLM is evolving and may vary based on institutional and local preferences and expertise. There is, however, an overall recognition that this modality may offer good local control for small tumors that can be ablated completely, with sufficient margins, results which are similar to those of surgery [10]. In a 2011 systematic review of 75 series published between January 1994 and January 2010 (36 RFA, 26 cryoablation, and 13 MWA), the 1-3 and 5-year survival rates for patients treated with one of the three modalities varied between $40-93 \%, 7-60 \%$, and $7-68 \%$, respectively. Median survival ranged from $4-43$ months, and the local recurrence rate ranged from 2-39\% [62]. Overall survival rates appear to be similar between the different ablative modalities, although randomized trials have yet to be performed.

Adapting from the surgical literature [63], a modified clinical risk score (CRS) was developed by assigning one point for each of: node-positive primary, disease-free interval from primary tumor to liver metastasis $<12$ months, number of tumors $>1$, size of tumor $>3 \mathrm{~cm}$, and CEA level $>30 \mathrm{ng} / \mathrm{ml}$. This allowed patient stratification
Fig. 3. Early detection of residual disease using 18F-fluorodeoxyglucose (FDG) positron emission tomography/ computed tomography (PET/CT) immediately after ablation. 40-yearold man with colorectal cancer liver metastases. a Intraprocedural PET/ CT image showing an FDG-avid segment 8 dome metastasis (arrow) prior to microwave ablation. b Tissue radioactivity concentration (TRC) ratio calculated to normalize uptake in the ablation zone to background liver uptake as follows: TRC ratio $=[($ ROI 1 TRCmax - ROI2 TRCmean)/ROI2 TRC mean] $\times 100$. TRC ratio was calculated to be 57.9. This value is higher than the threshold determined by Cornelis et al. [69] in the study that correlated high TRC ratio with recurrence within 1 year. c Fused PET/CT image 5 months later for repeat ablation of the marginal recurrence (arrow).

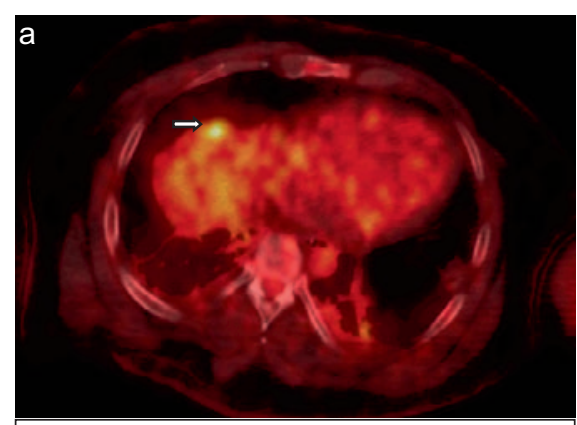

b

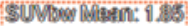
SUMbow MAtn:0.198

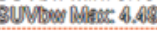

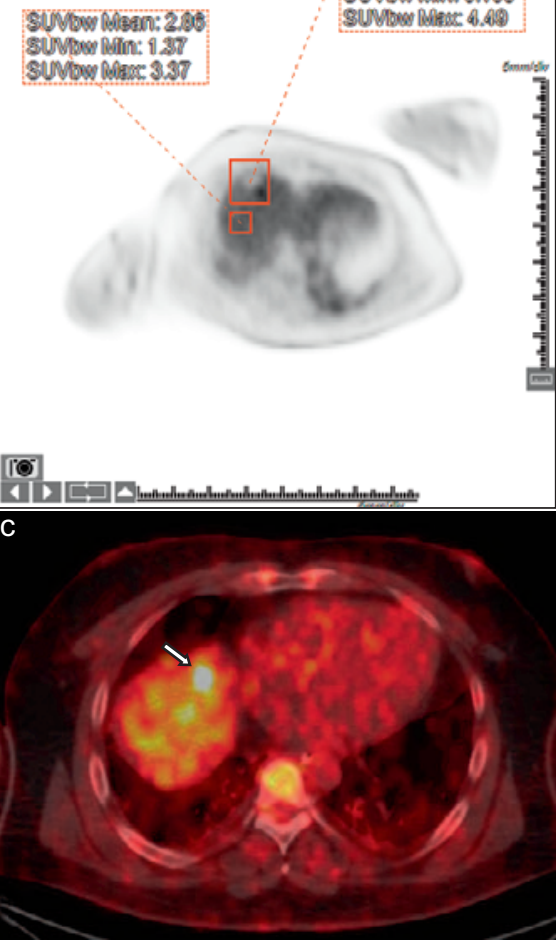

into low-risk (CRS 0 or 1), intermediate (CRS 2 or 3), and high-risk (CRS 4 or 5) for decreased overall survival and local tumor PFS after RFA $[6,19]$, corresponding to the relevant surgical literature. In general, it appears that smaller number of tumors, smaller size of treated tumors, absence of extrahepatic disease, no lymph-nodal involvement at initial excision, and longer time between initial diagnosis to the development of liver metastasis correlate with best outcomes $[6,19,64]$.

Complete ablation with $10-\mathrm{mm}$ margins (A0 ablation) all around the target tumor is the desired endpoint of any ablation modality, similar to achieving R0 tumor-free margin at resection. A minimal margin of at least $5 \mathrm{~mm}$ all around the tumor is an absolute requirement when ablation is offered with curative intent. Methods to ensure that this endpoint is accomplished are continuously investigated and certainly lacking when compared to surgical therapy. Unlike the resected specimen, the evaluation of the ablation zone and ablation margin is very challenging when determined by imaging alone. In addition to contrast-enhanced CT [65], ultrasonography [66] and magnetic resonance imaging [67] 
have been used to assess tumor margin and ablation completeness. Recently, positron emission tomography/computed tomography (PET/CT) guidance and immediate PET assessment of the tumor ablation procedure (fig. 2) was described [68]. In a review of patients with liver metastases treated with ablation, analysis of immediate postablation PET/CT scans have shown that a high residual activity ratio (i.e. tissue radioactivity concentration (TRC) ratio) can be an early surrogate image biomarker of progression within 12 months (fig. 3) [69]. However, there is still a significant discrepancy between complete ablation based on imaging alone and residual microscopic disease that may remain undetected at the ablation site [70]. This is supported by studies that analyzed the tissue extracted from the electrode after liver RFA [71-73] and correlated the identification of residual prolific [11] or viable tumor cells [74] with LTP $[11,74]$ as well as overall patient survival, after both lung and liver tumor ablation [75]. More recently, the strong correlation between the identification of viable tumor cells and LTP was prospectively validated through biopsies performed immediately after CLM ablation with pathologic and immunohistochemical assessment of the ablation zone [30]. This latest study showed that the risk for LTP at 12 months is as low as 3\% for patients with histopathologic evidence of complete tumor necrosis with margins $>5$ $\mathrm{mm}$ versus $73 \%$ for those with identification of microscopic viable tumor and margins $<5 \mathrm{~mm}$ at the end of ablation. The study documented a 23 times higher risk for LTP in the latter when compared to the completely ablated group with sufficient margins. Ideally, these tissue examinations should be performed immediately after ablation to detect residual tumor cells and allow appropriate thera- peutic modifications in the same session or adjuvant therapies after the ablation, similarly to the management of resected CLM with or without clear margins.

In view of the high likelihood of CLM recurrence even after resection, it is reasonable to consider the least invasive local therapy as a first-line therapy for CLM. A prior study indicated that when ablation was used to treat surgical patients with metastatic liver disease, $98 \%$ of those completely treated by RFA were spared unnecessary surgery. This was the result of complete treatment by ablation alone but more significantly due to short-interval multifocal disease progression that made the patients no longer candidates for locoregional therapies. In view of this natural history of the disease and the recent evidence that local tumor control after thermal ablation with adequate margins is comparable to surgical results, some recommend that for those selected patients with tumors that can be ablated with sufficient margins, ablation could be offered as the first local therapy within the described concept of the 'test of time' that requires close imaging and clinical follow-up [25]. This approach allows early detection of local or other progression that can be again treated locally by ablation or surgery, provided that the patient is still a candidate for locoregional therapy. The key advantage of this approach is that it allows the tumor to express its biology while providing the least invasive therapy.

\section{Disclosure Statement}

The authors have no conflict of interest in relation with the article.

\section{References}

1 Ruers T, Punt C, Van Coevorden F, et al: Radiofrequency ablation combined with systemic treatmen versus systemic treatment alone in patients with nonresectable colorectal liver metastases: a randomized EORTC Intergroup phase II study (EORTC 40004). Ann Oncol 2012;23:2619-2626.

2 Ruers T, Punt C, Van Coevorden F, et al: Radiofrequency ablation (RFA) combined with chemotherapy for unresectable colorectal liver metastases (CRC LM): long-term survival results of a randomized phase II study of the EORTC-NCRI CCSG-ALM Intergroup 40004 (CLOCC). ASCO Annual Meeting 2015. J Clin Oncol 2015;33(suppl):abstr 3501.

3 Mulier S, Ruers T, Jamart J, Michel L, Marchal G, Ni Y: Radiofrequency ablation versus resection for resectable colorectal liver metastases: time for a randomized trial? An update. Dig Surg 2008;25:445-460.

4 Solbiati L, Ahmed M, Cova L, Ierace T, Brioschi M, Goldberg SN: Small liver colorectal metastases treated with percutaneous radiofrequency ablation: local response rate and long-term survival with up to 10 -year follow-up. Radiology 2012;265:958-968.

$5 \mathrm{Kim} \mathrm{KH}$, Yoon YS, Yu CS, et al: Comparative analysis of radiofrequency ablation and surgical resection for colorectal liver metastases. J Korean Surg Soc 2011;81: 25-34.

6 Sofocleous CT, Petre EN, Gonen M, et al: CT-guided radiofrequency ablation as a salvage treatment of colorectal cancer hepatic metastases developing after hepatectomy. J Vasc Interv Radiol 2011;22:755-761.
7 Elias D, De Baere T, Smayra T, Ouellet JF, Roche A, Lasser P: Percutaneous radiofrequency thermoablation as an alternative to surgery for treatment of liver tumour recurrence after hepatectomy. Br J Surg 2002;89: 752-756.

8 Ito H, Are C, Gonen M, et al: Effect of postoperative morbidity on long-term survival after hepatic resection for metastatic colorectal cancer. Ann Surg 2008;247: 994-1002.

9 Butte JM, Gonen M, Allen PJ, et al: Recurrence after partial hepatectomy for metastatic colorectal cancer: potentially curative role of salvage repeat resection. Ann Surg Oncol 2015;22:2761-2771.

10 Gillams A, Goldberg N, Ahmed M, et al: Thermal ablation of colorectal liver metastases: a position paper by an international panel of ablation experts. The Interventional Oncology Sans Frontières meeting 2013. Eur Radiol 2015;25:3438-3454.

11 Sofocleous CT, Nascimento RG, Petrovic LM, et al: Histopathologic and immunohistochemical features of tissue adherent to multitined electrodes after RF ablation of liver malignancies can help predict local tumor progression: initial results. Radiology 2008;249:364-374.

12 Solbiati L, Livraghi T, Goldberg SN, et al: Percutaneous radio-frequency ablation of hepatic metastases from colorectal cancer: long-term results in 117 patients. Radiology 2001;221:159-166.

13 Gillams AR, Lees WR: Radio-frequency ablation of colorectal liver metastases in 167 patients. Eur Radiol 2004;14:2261-2267.
14 White TJ, Roy-Choudhury SH, Breen DJ, et al: Percutaneous radiofrequency ablation of colorectal hepatic metastases - initial experience. An adjunct technique to systemic chemotherapy for those with inoperable colorectal hepatic metastases. Dig Surg 2004;21:314-320.

15 Feliberti EC, Wagman LD: Radiofrequency ablation of liver metastases from colorectal carcinoma. Cancer Control 2006;13:48-51.

16 Hur H, Ko YT, Min BS, et al: Comparative study of resection and radiofrequency ablation in the treatment of solitary colorectal liver metastases. Am J Surg 2009; 197:728-736.

17 Oshowo A, Gillams A, Harrison E, Lees WR, Taylor I: Comparison of resection and radiofrequency ablation for treatment of solitary colorectal liver metastases. $\mathrm{Br}$ J Surg 2003;90:1240-1243.

18 Otto G, Duber C, Hoppe-Lotichius M, Konig J, Heise M, Pitton MB: Radiofrequency ablation as first-line treatment in patients with early colorectal liver metastases amenable to surgery. Ann Surg 2010;251:796-803.

19 Shady W, Petre EN, Gonen M, et al: Percutaneous radiofrequency ablation of colorectal cancer liver metastases: factors affecting outcomes - a 10-year experience at a single center. Radiology 2016;278:601-611.

20 Pawlik TM, Tanabe KK: Radiofrequency ablation for primary and metastatic liver tumors. Cancer Treat Res 2001;109:247-267.

21 Kuvshinoff BW, Ota DM: Radiofrequency ablation of liver tumors: influence of technique and tumor size. Surgery 2002;132:605-611; discussion 611-612. 
22 Kei SK, Rhim H, Choi D, Lee WJ, Lim HK, Kim YS: Local tumor progression after radiofrequency ablation of liver tumors: analysis of morphologic pattern and site of recurrence. AJR Am J Roentgenol 2008;190: 1544-1551.

23 Rossi S, Garbagnati F, Lencioni R, et al: Percutaneous radio-frequency thermal ablation of nonresectable hepatocellular carcinoma after occlusion of tumor blood supply. Radiology 2000;217:119-126.

24 Mulier S, Ni Y, Jamart J, Michel L, Marchal G, Ruers T: Radiofrequency ablation versus resection for resectable colorectal liver metastases: time for a randomized trial? Ann Surg Oncol 2008; 15:144-157.

25 Livraghi T, Solbiati L, Meloni F, Ierace T, Goldberg SN Gazelle GS: Percutaneous radiofrequency ablation of liver metastases in potential candidates for resection: the 'test-of-time approach'. Cancer 2003;97:3027-3035.

26 Kim YS, Rhim H, Cho OK, Koh BH, Kim Y: Intrahepatic recurrence after percutaneous radiofrequency ablation of hepatocellular carcinoma: analysis of the pattern and risk factors. Eur J Radiol 2006;59:432-441.

27 Ayav A, Germain A, Marchal F, et al: Radiofrequency ablation of unresectable liver tumors: factors associated with incomplete ablation or local recurrence. Am J Surg 2010;200:435-439.

28 Mulier S, Ni Y, Jamart J, Ruers T, Marchal G, Michel L Local recurrence after hepatic radiofrequency coagulation: multivariate meta-analysis and review of contributing factors. Ann Surg Oncol 2005;242:158-171.

29 Lee BC, Lee HG, Park IJ, et al: The role of radiofrequency ablation for treatment of metachronous isolated hepatic metastasis from colorectal cancer. Medicine (Baltimore) 2016;95:e4999.

30 Sotirchos VS, Petrovic LM, Gonen M, et al: Colorectal cancer liver metastases: biopsy of the ablation zone and margins can be used to predict oncologic outcome. Radiology 2016;280:949-959.

31 Nakazawa T, Kokubu S, Shibuya A, et al: Radiofrequency ablation of hepatocellular carcinoma: correlation between local tumor progression after ablation and ablative margin. AJR Am J Roentgenol 2007;188: 480-488.

32 Lu DS, Raman SS, Limanond P, et al: Influence of large peritumoral vessels on outcome of radiofrequency ablation of liver tumors. J Vasc Interv Radiol 2003;14: 1267-1274.

33 de Jong MC, Pulitano C, Ribero D, et al: Rates and patterns of recurrence following curative intent surgery for colorectal liver metastasis: an international multiinstitutional analysis of 1669 patients. Ann Surg 2009; 250:440-448.

34 Kim YS, Lee WJ, Rhim H, Lim HK, Choi D, Lee JY: The minimal ablative margin of radiofrequency ablation of hepatocellular carcinoma ( $>2$ and $<5 \mathrm{~cm}$ ) needed to prevent local tumor progression: 3D quantitative assessment using CT image fusion. AJR Am J Roentgenol 2010;195:758-765.

35 Liu CH, Arellano RS, Uppot RN, Samir AE, Gervais DA, Mueller PR: Radiofrequency ablation of hepatic tumours: effect of post-ablation margin on local tumour progression. Eur Radiol 2010;20:877-885.

36 Wang X, Sofocleous CT, Erinjeri JP, et al: Margin size is an independent predictor of local tumor progression after ablation of colon cancer liver metastases. Cardiovasc Intervent Radiol 2013;36:166-175.

37 Pawlik TM, Scoggins CR, Zorzi D, et al: Effect of surgical margin status on survival and site of recurrence after hepatic resection for colorectal metastases. Ann Surg 2005;241:715-722; discussion 722-724.

38 Muratore A, Ribero D, Zimmitti G, Mellano A, Langella S, Capussotti L: Resection margin and recurrence-free survival after liver resection of colorectal metastases. Ann Surg Oncol 2010;17:1324-1329.
39 de Baere T, Elias D, Dromain C, et al: Radiofrequency ablation of 100 hepatic metastases with a mean followup of more than 1 year. AJR Am J Roentgenol 2000; 175:1619-1625.

40 Berber E, Pelley R, Siperstein AE: Predictors of survival after radiofrequency thermal ablation of colorectal cancer metastases to the liver: a prospective study. J Clin Oncol 2005;23:1358-1364.

41 Ruers T, Punt C, Van Coevorden F, et al: Final results of the EORTC intergroup randomized study 40004 (CLOCC) evaluating the benefit of radiofrequency ablation (RFA) combined with chemotherapy for unresectable colorectal liver metastases (CRC LM). ASCO Annual Meeting 2010. J Clin Oncol 2010;28(suppl): abstr 3526 .

42 https://www.youtube.com/watch? $v=$ raHaBUxCXhA

43 Groeschl RT, Pilgrim CH, Hanna EM, et al: Microwave ablation for hepatic malignancies: a multiinstitutional analysis. Ann Surg 2014;259:1195-1200.

44 Tanaka K, Shimada H, Nagano Y, Endo I, Sekido H, Togo S: Outcome after hepatic resection versus combined resection and microwave ablation for multiple bilobar colorectal metastases to the liver. Surgery 2006; 139:263-273.

45 Bhardwaj N, Strickland AD, Ahmad F, et al: Microwave ablation for unresectable hepatic tumours: clinical results using a novel microwave probe and generator. Eur J Surg Oncol 2010;36:264-268.

46 Shibata T, Niinobu T, Ogata N, Takami M: Microwave coagulation therapy for multiple hepatic metastases from colorectal carcinoma. Cancer 2000;89:276-284.

47 Correa-Gallego C, Fong Y, Gonen M, et al: A retrospective comparison of microwave ablation vs. radiofrequency ablation for colorectal cancer hepatic metastases. Ann Surg Oncol 2014;21:4278-4283.

48 Huo YR, Eslick GD: Microwave ablation compared to radiofrequency ablation for hepatic lesions: a meta-analysis. J Vasc Interv Radiol 2015;26:1139-1146.e1132.

49 Seifert JK, Springer A, Baier P, Junginger T: Liver resection or cryotherapy for colorectal liver metastases: a prospective case control study. Int J Colorectal Dis 2005;20:507-520.

50 Niu R, Yan TD, Zhu JC, Black D, Chu F, Morris DL: Recurrence and survival outcomes after hepatic resection with or without cryotherapy for liver metastases from colorectal carcinoma. Ann Surg Oncol 2007;14: 2078-2087.

$51 \mathrm{Ng} \mathrm{KM}$, Chua TC, Saxena A, Zhao J, Chu F, Morris DL: Two decades of experience with hepatic cryotherapy for advanced colorectal metastases. Ann Surg Oncol 2012;19:1276-1283.

52 Finlay IG, Seifert JK, Stewart GJ, Morris DL: Resection with cryotherapy of colorectal hepatic metastases has the same survival as hepatic resection alone. Eur J Surg Oncol 2000;26:199-202.

53 Korpan NN: Hepatic cryosurgery for liver metastases. Long-term follow-up. Ann Surg 1997;225:193-201.

54 Bang HJ, Littrup PJ, Currier BP, Goodrich DJ, Choi M, Heilbrun LK, Goodman AC: Percutaneous cryoablation of metastatic lesions from colorectal cancer: efficacy and feasibility with survival and cost-effectiveness observations. ISRN Minim Invasive Surg 2012; 2012:pii: 942364.

55 Charpentier KP, Wolf F, Noble L, Winn B, Resnick M, Dupuy DE: Irreversible electroporation of the liver and liver hilum in swine. HPB (Oxford) 2011;13:168-173.

56 Lee EW, Chen C, Prieto VE, Dry SM, Loh CT, Kee ST: Advanced hepatic ablation technique for creating complete cell death: irreversible electroporation. Radiology 2010;255:426-433.

57 Kingham TP, Karkar AM, D'Angelica MI, et al: Ablation of perivascular hepatic malignant tumors with irreversible electroporation. J Am Coll Surg 2012;215: 379-387.
58 Silk MT, Wimmer T, Lee KS, et al: Percutaneous ablation of peribiliary tumors with irreversible electroporation. J Vasc Interv Radiol 2014;25:112-118.

59 Cannon R, Ellis S, Hayes D, Narayanan G, Martin RC 2nd: Safety and early efficacy of irreversible electroporation for hepatic tumors in proximity to vital structures. J Surg Oncol 2013;107:544-549.

60 Thomson KR, Cheung W, Ellis SJ, et al: Investigation of the safety of irreversible electroporation in humans. J Vasc Interv Radiol 2011;22:611-621.

61 Hosein PJ, Echenique A, Loaiza-Bonilla A, et al: Percutaneous irreversible electroporation for the treatment of colorectal cancer liver metastases with a proposal for a new response evaluation system. J Vasc Interv Radiol 2014;25:1233-1239.e1232.

62 Pathak S, Jones R, Tang JM, et al: Ablative therapies for colorectal liver metastases: a systematic review. Colorectal Dis 2011;13:e252-265.

63 Fong Y, Fortner J, Sun RL, Brennan MF, Blumgart LH: Clinical score for predicting recurrence after hepatic resection for metastatic colorectal cancer: analysis of 1001 consecutive cases. Ann Surg 1999;230:309-318; discussion 318-321.

64 Gillams AR, Lees WR: Five-year survival in 309 patients with colorectal liver metastases treated with radiofrequency ablation. Eur Radiol 2009;19:1206-1213.

65 Kim KW, Lee JM, Klotz E, et al: Safety margin assessment after radiofrequency ablation of the liver using registration of preprocedure and postprocedure CT images. AJR Am J Roentgenol 2011;196:W565-572.

66 Meloni MF, Andreano A, Franza E, Passamonti M, Lazzaroni S: Contrast enhanced ultrasound: should it play a role in immediate evaluation of liver tumors following thermal ablation? Eur J Radiol 2012;81:e897902

67 Vilar VS, Goldman SM, Ricci MD, et al: Analysis by MRI of residual tumor after radiofrequency ablation for early stage breast cancer. AJR Am J Roentgenol 2012;198:W285-291.

68 Ryan ER, Sofocleous CT, Schoder H, et al: Split-dose technique for FDG PET/CT-guided percutaneous ablation: a method to facilitate lesion targeting and to provide immediate assessment of treatment effectiveness. Radiology 2013;268:288-295.

69 Cornelis F, Storchios V, Violari E, et al: 18F-FDG PET/ $\mathrm{CT}$ is an immediate imaging biomarker of treatment success after liver metastasis ablation. J Nucl Med 2016;57:1052-1057.

70 Goldberg SN, Grassi CJ, Cardella JF, et al: Imageguided tumor ablation: standardization of terminology and reporting criteria. Radiology 2005;235:728-739.

71 Sofocleous CT, Klein KM, Hubbi B, et al: Histopathologic evaluation of tissue extracted on the radiofrequency probe after ablation of liver tumors: preliminary findings. AJR Am J Roentgenol 2004;183:209-213.

72 Snoeren N, Jansen MC, Rijken AM, et al: Assessment of viable tumour tissue attached to needle applicators after local ablation of liver tumours. Dig Surg 2009;26: $56-62$.

73 Sofocleous CT, Garg SK, Cohen P, et al: Ki 67 is an independent predictive biomarker of cancer specific and local recurrence-free survival after lung tumor ablation. Ann Surg Oncol 2013;20(suppl 3):S676-683.

74 Snoeren N, Huiskens J, Rijken AM, et al: Viable tumor tissue adherent to needle applicators after local ablation: a risk factor for local tumor progression. Ann Surg Oncol 2011;18:3702-3710.

75 Sofocleous CT, Garg S, Petrovic LM, et al: Ki-67 is a prognostic biomarker of survival after radiofrequency ablation of liver malignancies. Ann Surg Oncol 2012; 19:4262-4269. 